\title{
The Rhetorical Analysis of Criticism in Persian and English Linguistics Papers
}

\author{
Shabnam Dezfoolian \\ Department of English Language and Literature, Allameh Tabataba'i University, Iran \\ Email: shabnam.dezfoolian@gmail.com
}

Received: 02-04-2017

Published: 01-11-2017
Accepted: 24-05-2017

doi:10.7575/aiac.ijalel.v.6n.6p.45
Advance Access Published: September 2017

URL: http://dx.doi.org/10.7575/aiac.ijalel.v.6n.6p.45

\begin{abstract}
Successful academic writing depends on being familiar with different rhetorical strategies .One of these strategies used by authors of scientific articles is the act of criticism, the criticism of the previous works or other members of their respective communities. Actually this helps writers to justify their own study and to create a gap. Therefore the sociopragmatic variable of Academic Conflict (AC) has been investigated in different academic genres and disciplines. This study aims to examine this variable in linguistics papers in Persian and English. To this end a corpus of 60 papers, 30 in Persian and 30 in English, have been chosen randomly. First in the quantitative phase of the study, the direct and indirect $\mathrm{AC}$ variables that have been used for critical speech acts were compared by within and between languages and then in a qualitative examine, the discourse analysis of important features were examined to show the probable relations to the cultural contexts. The results showed that English writers used more criticism acts than Persian writers and both groups used direct AC more than indirect one. Although both groups of papers are written in different cultural contexts, the strategies used by authors seem familiar and have minute differences and this may show that the effect of discipline and the language of instruction are more than cultural contexts in rhetoric of criticism.
\end{abstract}

Keyword: academic criticism, academic conflict, Evaluation, Attitudinal lexis, professional disagreement

\section{Introduction}

The importance of research articles as one of the genre in academic setting has become more distinctive nowadays, and as Martín-Martín, P (2005) states the research papers are the main devices used for communication between scientists in different discourse communities in the current century. Hyland and Salager-Meyer (2008) discussed the importance of academic genre and its attraction to researches and presented that these studies provide communities with academic practices. They believe that the main task of academics is to write, therefore the academic discourse has become more and more important to text analysts.

Text analysis as a way of demystifying different genres such as academic genre has been the center of attention these days. Rhetoric analysis of the texts has had lots of advantages for linguistics and applied linguistics in both research and pedagogy. Ceccarelli (2001) discusses that although there are differences between academic texts and public texts but these differences cannot prevent us from analyzing academic texts meticulously; however, the analyst should be aware of the context in which a text is used and the subject matter and the author should also be considered.

The rhetoric of criticism in academic setting became important when the number of studies increased in recent years and as Salager-Meyer and Alcaraz Ariza (2007) clarify, it became a difficult task to choose the suitable and appropriate paper among so many published ones around the world, therefore the researcher should be familiar with the principles of critical approach to reading papers and should be aware of the methods of criticism.

Academic Criticism and evaluation of research papers have been defined by many scholars of text analysis. Hunston and Thompson (2000) discusses the issue of evaluation in academic setting and present three functions for evaluation: the first one is to talk about others opinions, the second one is to maintain relationship between readers and authors or listeners and speakers and the last one is to organize the discourse. They also mention the two factors of ideology and the value system of the community as the main elements effective in this essential process.

The methods used for evaluation has been also different historically. Connor (1996) believes that empirical research on contrastive rhetoric conducted in the area of Psychology, Anthropology can be divided into three groups. The first are related to social functions of writing, the second one are on the role of instruction and the last one are on literacy of L1 area.

A variable which attracted the attention of researchers is academic conflict or criticism (AC). Academic conflict is defined by Hyland (2000) as how scholars express their disagreement to other authors of academic papers in one special field. $\mathrm{AC}$ is divided into two: direct $\mathrm{AC}$ in which the author of paper criticizes the opposing ideas very overtly and indirect $\mathrm{AC}$ in which the writer uses mitigating devices such as hedging devices to dissent in a covert manner.

This variable has been under study from different perspectives and in different areas of scientific papers. Among them, some researchers have studied general academic works and compared different fields With each other regarding AC 
variable (Afros and Schryer, 2009; Harman, 1989; Giannoni, 2005; Thetela, 1997). One study considered AC in online instruction (Sellani, and Harrington, 2002). However, the literature is replete with studies on criticism of medical discourse. The researchers actually have done studies on AC variable in different medical genres (Salager-Meyer, 1999 ;Salager-Meyer, 2002; Salager-Meyer, 2000; Salager-Meyer, and Zambrano, 2001; Salager-Meyer and Alcaraz Ariza and Zambrano, 2003; Salager-Meyer and Ariza, 2003 ; Salager-Meyer, 2000). Some researchers have constrained the area of research on special parts of the papers such as abstracts ( Martín-Martín and Burgess, 2004; Stotesbury, 2003) .Despite the studies done on this area, Hyland (2000) believes that our knowledge regarding criticism is very low and more work needs to be done on this area.

1.1 Purpose of the Study

Most of the studies in the area of academic criticism are on medical papers or medical editorials and if we want to broaden our knowledge of criticism in academic setting we should do the research on the other areas of science. To the researchers' knowledge, no study has been done on the Persian language and especially on the linguistics for criticism features. Therefore the aim of the present study is to address this gap and to investigate this variable in Linguistics papers in Persian and English .To do a contrastive analysis of rhetorical analysis, the field of Linguistics were chosen because this major is taught in Persian in Iran and papers are published in Persian too. A further aim will be to find the relationship between differences and contextual factors. Therefore analyses of the papers especially regarding the conflict variable will provide us with invaluable information.

\subsection{Research Questions}

The present study was conducted to answer the following research questions:

1. Is there any statistically significant difference regarding rhetoric of criticism, between Linguistics papers in Persian and English?

2. What are the cultural and social effects on different patterns of academic conflict variable in linguistics papers in Persian and English languages?

\section{Literature Review}

Criticism and its effects in academic setting is of high importance. In each communication there will be conflicts but these become more noteworthy in academic area.To solve the conflicts we as researchers should be able to understand the structure of evaluations, and be familiar with the methods of presenting them effectively.

There have been different efforts to define criticism and evaluations; however, researchers could not reach unanimity regarding the structure of criticism. Hunston (1993, p.58) presents a definition for evaluation as follows: evaluation is "anything which indicates the writer's attitude to the value of an entity in the text." She also believes that there are three procedures for showing criticism, status, value and relevance .She further explains that status shows how much the writer is sure and certain about beliefs and this goes through all research report, the value is considered as the attitudes of writers on a scale of good-bad. As all of us have value system which is culturally bound and we criticize others based on that. The last one, relevance, is the evaluation of how much the argument in the research papers is relevant and significant. Hunston talks about relevance markers to show the significance and relations of the arguments to the respected scientific community.

Cheney \& McMillan (1990) examined the nature of rhetoric organization and the methods of text analysis and the relation of them to communication organization. They also showed how persuasion is used and constrained.

McKerrow (1989) pus forward 8 principles for the act of criticism and he believes that the theory includes the critics of freedom and critics and domination. He sees the act of criticism as a transformative action rather than a method.

$\mathrm{AC}$ conflict variable is classified into direct AC in which the author straightforward writes his disagreement and indirect $\mathrm{AC}$ the writer does not take the responsibility of criticism directly and puts it on other factors the following examples show clearly these two variables:

- "Abels and Neeleman in their commentary offer us exactly the wrong way of doing this. They argue that any attempt to unify linguistics and cognitive science must follow the principle of "methodological modularity" (direct AC)

- "It seems that the data is not sufficient"(indirect AC)

Hunston (1993) also called AC variable as "professional disagreement."

Generally, some researchers have worked on different majors and investigated academic papers. Afros and Schryer (2009) has done one study on the articles in North America academic journals published during 2001 to 2006 years. The experiment revealed that the authors have used two rhetorical devices to show the gaps they intended to fill in their respected fields; one is to talk positively about their works and the other is to criticize negatively the opposite views. They identified the devices as using personal pronouns, evaluative word, comment clauses, lexical cohesive, coordination and discourse chunks sequencing. They concluded that in ESP setting, we should consider the very specificity and writing should be taught towards the very special needs of learners. In another study, Harman (1989) addressed the issue of organizational culture and studied the works written by very famous experts in an American university. It showed the different levels of culture and the necessity of adding the perspective of the culture to AC studies.

Thetela (1997) discusses the two kinds of discourse, related to subject of academic papers and context, and talks about evaluation variable as connected to both. By Scrutinizing 60 papers, he identified the entities, which are evaluated and classified them into process and product, and presented a value scale for them.

Giannoni (2005) examined 20 articles from Anglo American and Italian journals in one field of study. The researcher focused on the linguistics and pragmatic features of criticism especially on the ones used for presenting negative 
evaluations . The results showed some similarities and differences in the strategies employed by American and Italian authors. Online teaching, the product of CALL, has been under study regarding the criticism too. Sellani \& Harrington (2002) reported that in online instructions, there were some conflicts to be identified between academics and the faculty and they tried to show how they can be solved.

Most of the previous studies have been done in the area of medicine. Salager-Meyer (1999) did a research to investigate AC or the academic conflicts in medical papers in journals from 1810 to 1995 . The period was divided into 2 blocks; 1810-1929 and 1930-1995. The study is of mixed method study ones, and the quantitative part showed that the number of direct criticism was more than the indirect ones in both blocks $(\mathrm{p}=.0001)$, and the frequency of direct criticism was higher in the first block 1810-1929 than the second one 1930-1995. The results also showed that indirect AC like using hedging and mitigated devices increased by the passing of time in second block, and direct one such as using personal pronouns and aggressive tone decreased.

Salager-Meyer (2002) analyzed the speech acts used in medical education and found that not using hedging and mitigating and using self direct and sarcastic tone correlates positively with the social role of the writers in their respective communities as the dominant experts who always advise others and are knowledge holders.

Salager-Meyer (2000) in another study probes AC or academic conflict realizations in 90 medical articles published in the period of 1810-1995. Like some of the previous studies, the time divided into two periods. The results showed that the direct criticism acts were more than indirect ones in two groups $(p=.0001)$ and indirect acts are more than direct ones in the second group. The study also revealed that the frequency of indirect criticism acts started slow from $1910 \mathrm{~s}$ and but had a continuous ascent. The qualitative aspect of research showed that 19 and 20 centuries was the time for criticism to be personal in an authority manner and contemporary century was distinctive for using mitigation in conflicts.

Salager-Meyer and Zambrano (2001) investigated the AC features in 20 English and French medical papers in 185 years span. To study the evolution of the rhetorical strategies of criticism, they divided the 185 years into 9 blocks. The interesting result showed that during the years 1810-1929, there was no difference between direct and indirect ones in two languages; however, in 1930-1995the direct AC was more in French and indirect one was more in English than ones in French(.001). The study showed that the century 19 and 20 had more personal way of criticism as opposed to $21^{\text {st }}$ century, and intellectual climate can affect the rhetoric of criticism a lot.

Salager-Meyer, Alcaraz Ariza, and Zambrano (2003) did an experiment on the research medical papers in three languages of Spanish, French and English from 1930 to 1995. They concluded that French and Spanish writers were more critical, and wrote in an authority manner than English authors. From 1990, the method of criticism of Spanish writers were changed and became more indirect like English ones. Although French researchers did not change their style completely however, they moved toward indirect AC.

Salager-Meyer and Ariza (2003) studied AC variable in four different genres in medical Spanish articles. They examined medical genres included editorials, review papers, research articles and case studies. They selected 76 papers written from 1930-1999. The results indicated that the number of AC variable is more in editorial genre than others, and from 1970 t0 1999 the number of AC enhanced in all genres more than that of AC in 1930 to 1970 period. They cited the divergent communicative functions of divergent genres and social roles of authors in relations to audience, as reasons for diversity in rhetoric of criticism.

In another similar study Salager-Meyer (2001) chose 50 articles in medical journals in four genres as research papers, review paper, editorials and case study. He concluded that in editorial genres, there are more direct and authority form of criticism because they are written by experts in the field. Then the writers of reviews write in amore assured way, and in contrast the research articles are created in acclimate of humble and imposing tone. The last group of genres, case studies, have the least number of AC features

Some studies have been done on abstracts of articles, and have addressed the issue of criticism in that special parts of academic papers. Martín-Martín and Burgess (2004) chose 160 research articles abstracts in English and Spanish, in the fields of Phonetics and Phonology. The results confirmed the use of Indirect ones more in English than Spanish abstracts, and researchers concluded that reason for this phenomenon is that the socio pragmatics contexts of the two groups of researchers are different, and also the relation between the authors and the research community they wrote to, is different. They believed that the relation is determined by the size of the community and the pressure in it.

Stotesbury (2003) investigated the abstracts of research papers in humanities and natural sciences. The study showed the number and kinds of explicit evaluations features were different across disciplines, and suggested for teaching those to novice researchers of different majors.

\section{Methodology}

\subsection{Corpus}

To the purpose of the study, 60 papers in the field of Linguistics were randomly chosen. 30 linguistics articles in English, and 30 papers in Persian were selected. In order to have the most authentic data and omit the factor of transfer from L1, it was decided to choose papers written by native speakers of English and Persian; therefore, papers in English were chosen that were written by the authors with English names and Persian papers written by Persian names and not translated ones. The affiliations of the authors were considered as an additional factor helped the data of the research to be authentic. After consulting with one professor in Linguistics ,the English papers selected from the magazine 
"Lingua," as it is one of the most important and international journals in Linguistics, and Persian articles from magazine "language and linguistics" related to Iranian linguistics community; this is also one of the most referential magazine in Persian and in Iran.

The magazine, Zaban va Zabanshenasi, "language and linguistics" has been published from 2003, therefore to do the contrastive analysis of two languages, the same period were chosen for "Lingua" magazine: 2003-2014.

\subsection{Procedure}

First each paper was read by the researcher then, the AC variables in each 60 paper were found, and the frequencies of indirect AC and direct one were measured separately in English and Persian papers. If one criticism was used to refer to one person or one source, all were considered and calculated differently, because the different strategies used was subject of the study ; however, if one criticism was cited by other scholars not the writer himself it was not considered as AC . Valle (1999) says: "A project in which the study is outside the writer's own discipline necessarily requires help from members of the scientific community under study." Therefore in order to increase the reliability and validity of the results, one Linguistics professor reviewed and commented on the direct and indirect AC variable. Then the data were tabulated and the different groups were discussed and classified.

\subsection{Data Analysis}

When the frequencies were counted in each of the direct and indirect $\mathrm{AC}$ in two groups of papers ,chi-square was used to see if there are significant differences between direct and indirect in each group and between direct ones and indirect ones in two groups. Then each kind of categories was discussed to see why the authors of two languages chose those specific ways of rhetoric of criticism in their papers.

\section{Results}

After identifying direct and indirect AC, they were calculated per each language and the data was tabulated. Table 1 shows the number of words in each corpus, English and Persian, and also the number of total AC variables in each corpus.

Table 1. Total Academic Conflicts (AC)

\begin{tabular}{lc}
\hline & Number of AC \\
\hline Persian & 116 \\
\hline English & 159 \\
\hline Total & 275 \\
\hline
\end{tabular}

As the table shows, the number of AC in Persian articles is more than English ones. These shows that Persian linguists tend to criticize more than English linguists. In order to compare the indirect and direct AC in two groups of papers, we measure each one separately, the results have been shown in table 2 .

Table 2. Total Number Direct And Indirect Academic Conflicts (AC)

\begin{tabular}{lcc}
\hline & Persian & English \\
\hline Direct AC & 82 & 120 \\
\hline Indirect AC & 34 & 39 \\
\hline total & 116 & 159 \\
\hline
\end{tabular}

As it is clear from numbers in table, writers of Persian articles have 82 direct AC, and 34 indirect one; therefore the writers have preferred overt criticism more than covert negative evaluation. Similarly, English writers have used direct $\mathrm{AC}$ than more indirect one. It seems that none of the groups has a way of conservative evaluation.

In order to make the comparison easier and tangible, the results have been changed to percentages.

Table 3. Percentages of Direct And Indirect Academic Conflicts (AC)

\begin{tabular}{lcc}
\hline & Persian & English \\
\hline Direct AC & $70.68 \%$ & $75.47 \%$ \\
\hline Indirect AC & $29.31 \%$ & $24.52 \%$ \\
\hline total & 116 & 159 \\
\hline
\end{tabular}

It is obvious that Persian writers in 70 percents of the cases have criticized directly and in only 30 percent have used indirect AC and similarly their English counterparts have used 75 percents direct and 24 percents indirect ones. The following graph shows clearly the difference of variables in two groups of papers. 


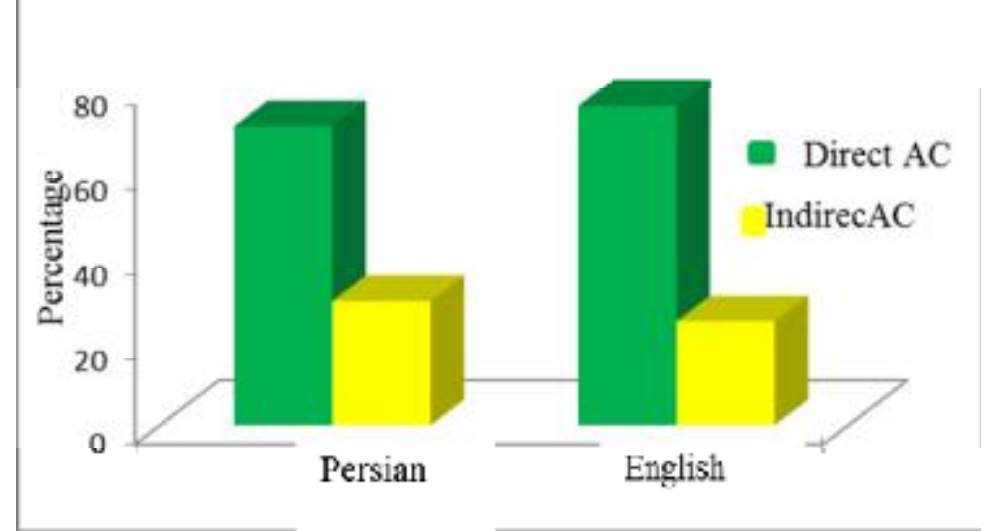

Figure 1. Cross-language comparison of the percentages of direct and indirect academic

By looking at sentences, structures and examining the cases, which have been used by Persian researchers, some interesting patterns emerged. Firstly in overt criticism it seemed that they have used different strategies for criticizing. The targets of criticisms in Persian papers have been four: the reasoning and justifying of previous theories, the statistical parts of past studies, the ignored problems in area of study and doubt in comments. For each group different structures have been used. The following table shows them comprehensively.

Table 4. the Targets of Criticisms and Structures Used in Persian Papers

\begin{tabular}{lllc}
\hline justifying of previous theories & frequency & doubt in comments & frequency \\
\hline The reasoning cannot be accepted. & 3 & It has not been specified clearly. & 2 \\
\hline It is not defendable. & 1 & There is uncertainty. & 1 \\
\hline It cannot be justified. & 5 & It has not been surely stated. & 3 \\
\hline It cannot be confirmed. & 3 & the ignored problems in the study & frequency \\
\hline It needs modification. & 2 & The problem has been omitted. & 2 \\
\hline It should be reconsidered again. & 1 & It has been overlooked. & 4 \\
\hline If it was so ... it would ... & 3 & the statistical parts of past studies & frequency \\
\hline It is not logical. & 1 & It has been solved without special & 3 \\
\hline It is mere imitation. & 3 & Statistics have a kind of conflicts. & 3 \\
\hline
\end{tabular}

As it is obvious from the table, the most targeted area of criticism in Persian articles is the reasoning and justifying part. The structure cannot be accepted and cannot be justified have the most cited ones by frequencies 3 and 5 respectively. The problem has been ignored with total 6 frequencies are the highest one. The mentioned structures are not the only one used by writers and have been chosen because of being more distinguished patterns in the discourse analysis .the followings are some parts of the structures to clear the issue: for example:

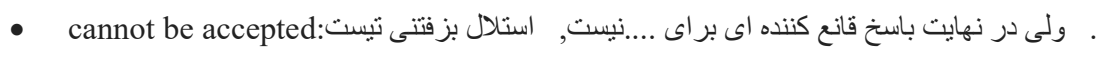

"the reasoning cannot be accepted, however it is not a convincing answer for ..."

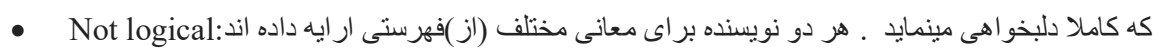

"Both writers have put forward a list of different definitions for ..., it seems too arbitrary"

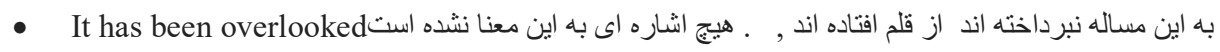

"It is not mentioned, Are missing, the issue has not been considered"

- If it was so ... it would. اكر تمامى اين تركيب ها صفت مى بودند انكاه استدلال فوق مبنى در .....

"If All these compounds were adjectives, then the reasoning based on ... Could be accepted"

About indirect AC, the kinds of mitigating devices used are of interest. The following words and structures are used as rhetorical devices: seem, maybe, probably, it was better and in contrast to some. The targets of criticisms in English papers have been found three: the reasoning and justifying of previous theories, the ignored problems in area of study and doubt in comments. For each group different structures have been used. The following table shows them: 


\begin{tabular}{lllc}
\hline Table 5. The Targets of Criticisms & and Structures Used in English Papers & & \\
\hline justifying of previous theories & frequency & doubt in comments & frequency \\
\hline study were not meaningful & 3 & we still lack precise information & 4 \\
\hline it cannot account for & 3 & he does not provide examples & 1 \\
\hline It cannot be justified. & 4 & Further investigation is needed & 3 \\
\hline It is not logical. & 3 & .....did not detail the process & 3 \\
\hline he does not provide examples & 3 & It has not been explored further. & 1 \\
\hline we argue against & 3 & the ignored problems in the study & frequency \\
\hline This would be a fundamental mistake & 4 & It has been overlooked. & 2 \\
\hline
\end{tabular}

Like Persian authors, English researchers criticize their collogues on the reasoning parts more. Although the general structures used are similar however, there are some minute differences, and this variety is obvious more in the strategies used for showing doubts toward other works. The ignored problems are like Persian papers and have been criticized by both groups as well. These are only the most obvious ones and corpus presents more varieties . The followings are some examples to show the structures used by English writers:

\section{Reasoning:}

- 'However, the inability of 'say' to introduce subject complements in these creoles does not necessarily negate its status as a complementizer"

- "The problem with this position is"

- “One thing apparently lost from Harley's (2007) analysis of Latinates is the general failure of Latinate and particles to co-occur. Harley treated the Latinate prefixes as particles in the same position as the Germanic particles in other constructions"

- "Most of these disputes are undignified and ill-informed, and do not serve the discipline well"

- "it cannot account for Latinate"

- Doubt in comments:

- "There is need for formal comparison, Further research is necessary"

- "further research on early varieties of Sranan Tongo is needed"

- "However, he does not provide examples or attempt a full comparison between Ewe and Sranan"

the numbers show little difference between using indirect AC in English and Persian paper; however, the kinds of mitigating devices used are of more variety in English articles for example these two kinds of sentences, show how English writers are conservative in their criticism:

- "I differ from Harley by arguing that though Latinate"

- "Deserve more detailed discussion"

\section{Discussion}

Actually genre and rhetorical analysis have been investigated across different languages and on different parts of academic papers such as, introduction, method, results and conclusion. It attracted the attention of researchers recently and examined it from different perspectives.

The results of the present study showed very clearly that in the corpus of the research, the English linguists tended to criticize more than Persian linguists, and they not only want to criticize more but also they do this in a very overt and authority manner and even sometimes in a sarcastic tone.

In contrast, Persian writers tended to criticize less and in those cases they did not seem to be very conservative. In contrast to most of the previous studies (Salager-Meyer, Alcaraz Ariza, \& Zambrano, 2003; Martín-Martín, \& Burgess, ,2004; Salager-Meyer \& Zambrano, 2001) the English writers did not use different rhetorical devices to lessen their effects of criticism and to save the face of other researchers.

Actually the percentages of the direct and indirect AC in both English and Persian articles in the corpus were close by 70.68 - 75.47 and $29.31-24.52$ for direct -indirect tones. The similarities in the results of this study can be explained by the one specific field of study which is Linguistics. The results actually are in line with the Hunston (1989) conclusion of the study on research articles from three different field, biochemistry, sociolinguistics and history. The results of her study showed that linguistics strategies used for showing disagreement depend on the specific discipline. It means that the strategies used in biochemistry were unique to that field and because the corpus of study is chosen from one field of study, the results showed similarities. Although the language used in classes is Persian, because most of the academic text books and papers in linguistics departments in Iran are taught in English, it seems that researchers and graduated students have been accustomed to type of writing in English and have transferred them to their Persian papers.

Although using direct AC was observed in the two groups of papers in the corpus but the ones were not the kinds of direct attack or the serious ones. Regarding this, Hunston (1989) believes that "incorrect knowledge claims" and direct attack cannot be found in the current written English papers. 
Researchers for convincing the readers use power , and using direct AC more in English and Persian can be justified in this way. The current time is the time of competition especially in academic situations. It seems that the Persian writers want to take part in this rival and have learned by experience if they want to be heard, they should talk from the authority status. Consequently, they aspire to use direct AC more like English authors. Hyland (2002) says that although use of self pronoun is not a very good way of expressing ideas in academic papers it can help the writer to make identity in his or her own community. Therefore his research showed underuse of personal pronouns in Hong Kong undergraduates learning English as a second language. They thought that it had authority connotations.

Although the Iranian culture is famous for compliments, Taarof in Persian term, it seems that it is not dominant or effective in academic setting. Therefore Iranian researchers are like their English counterparts under the impact of academic status and their disciplines in criticism. It means that the pressure from the community to be a distinguished member and the subject of Linguistics itself are the determinant factors in using special rhetoric of criticism.

The most targeted issue in criticism especially in Persian was justifying insufficiently, it means that the writers believed that support was not sufficient. Some cases are related to not mentioned data but most important one was related to the reasoning part that did not seem rational.

In using indirect $\mathrm{AC}$ variable, there were similarities between two languages especially in using hedging. Hedging are mitigating devices that as Hyland (1996) presents are used by writers to let them predicts probable disagreement to their own claims , and show deference to their collogues. He puts further that hedging has been used by authors as means of politeness to show that they don't intend to impose their beliefs on others.

The following words and structures are used as rhetorical devices: seem, maybe, probably, it was better, in both groups. It is really in the opposite of the belief presented by Vassileva (1997) that hedging is culture specific .It is also against the idea put forward by Clyne $(1981,1987)$ that academic writing strategies and styles are related to the attitudes of a community toward learning and knowledge that is transferred by educational system, and this itself depends on cultural contexts. It has been stated that (Kreutz \& Harres, 1997) using more hedging show that the language is more interactional and dialogic; However, using hedging in papers of two languages were approximately similar and it cannot be concluded that which one is more interactional.

\section{Conclusion and Implication}

The importance of writing especially in an academic setting has been proved by many experts. Hyland (2004) state that in the past academic writing was considered as a homogenous skill at colleges and universities, and now it is believed that each discipline has its own way of writing and the members make those traditions instructionally. The rhetoric of criticism is one of the characteristics which is special in every field and every language. This study was done to show the rhetorical contrastive analysis of English and Persian linguistics papers. The results showed that the English linguists tend to criticize more and also do this overtly, and Persian linguistics criticize less but in a very similar way. The research has implications for writing instructions specific for each major at universities; as Hyland (2002) states that each discipline has its own way of negotiation of identity and for example all don't use impersonality tone equally. Therefore, it is the responsibility of teachers and instructors to make students and language learners aware of characteristics and specially AC variables. Moving toward ESP and specificity can show the need for such instructions. Learners should know that if they want to be a member of a community, they should be familiar with the way language used by its other members. The research has also implications for decoding the mysteries of social and cognitive factors in each specific field. One point should be regarded that Linguistics consists of so many sub fields and each one has the characteristics of hard and soft sciences like Computational Linguistics and General Linguistics. As Stotesbury (2003) investigated the abstracts of research papers in humanities and natural sciences. He Concluded that the act of criticism were different across disciplines and suggested for teaching those to novice researchers of different majors; However, in this study, the corpus include all and did not separate them and further study can be done in different subfields. And also the gender, age and profession and status of the writers may have some effects on the rhetoric of criticism, and this can be studied by other interested researchers.

\section{References}

Afros, E., \& Schryer, C. F. (2009). Promotional (meta) discourse in research articles in language and literary studies. English for Specific Purposes, 28(1), 58-68.

Candlin , C., \& Gotti, M. (Eds.). (2007). Intercultural aspects of specialized communication (Vol. 14). Peter Lang.

Ceccarelli, L. (2001). Rhetorical criticism and the rhetoric of science. Western Journal of Communication (includes Communication Reports), 65(3), 314-329.

Cheney, G., \& McMillan, J. J. (1990). Organizational rhetoric and the practice of criticism. Journal of Applied Communication Research, 18(2), 93-114.

Clyne, M. (1987) . Cultural differences in the organization of academic texts: English and German. Journal of Pragmatics, 11(2), 211-241.

Connor, U. (1996). Contrastive rhetoric: Cross-cultural aspects of second language writing. Cambridge University Press. 
Giannoni, D. S. (2005). Negative evaluation in academic discourse. A comparison of English and Italian research articles. Linguistica e Filologia, 20, 71-99.

Hyland, K. (1996). Writing without conviction? Hedging in science research articles. Applied linguistics, 17(4), 433454

Hyland, K. (2000). Disciplinary discourses. Social interactions in academic writing. London: Longman

Hyland, K. (2002). Options of identity in academic writing. ELT journal, 56(4), 351-358.

Hyland, K. (2002). Authority and invisibility: Authorial identity in academic writing. Journal of pragmatics, 34(8), 1091-1112.

Hyland, K. (2004). Disciplinary discourses: Social interactions in academic writing. University of Michigan Press.

Hyland, K , \& Salager-Meyer, F. (2008). Scientific writing. Annual review of information science and technology, 42(1), 297-338.

Hunston, S.(1989). Evaluation in experimental research articles (Doctoral dissertation, University of Birmingham).

Hunston, S., \& Thompson, G. (Eds.) . (2000). Evaluation in Text: Authorial Stance and the Construction of Discourse: Authorial Stance and the Construction of Discourse. Oxford University Press.

Harman, K. M. (1989). Culture and conflict in academic organisation: Symbolic aspects of university worlds. Journal of Educational Administration, 27(3).

Kourilova, M. (1998). Communicative characteristics of reviews of scientific papers written by non-native users of English. Endocrine Regulations, 32, 107-114.

Kreutz, H.,\& Harres, A. (1997). Some observations on the distribution and function of hedging in German and English academic writing. Trends in linguistics studies and monographS, 104, 181-202.

Martín-Martín, P. (2005). The rhetoric of the abstract in English and Spanish scientific discourse: A cross-cultural genre-analytic approach (Vol. 279). Peter Lang.

Mauranen, A. (2002). “A good question”. Expressing evaluation in academic speech. In G. Cortese, \& P. Riley (Eds.), Domain-specific English: textual practices across communities and classrooms (pp. 115-140). Bern: Peter Lang.

McKerrow, R. E. (1989). Critical rhetoric: Theory and praxis. Communications Monographs, 56(2), 91-111.

Salager-Meyer,F. (1999). Contentiousness in written medical English discourse: A diachronic study (1810-1995). Textthe Hague then Amsterdam then berlin, 19(3), 371-398.

Salager-Meyer , F. (2000). Rhetorical evolution of oppositional discourse in French academic writing: Oppositional discourse in academic writing. Hermes, Journal of Linguistics, 25, 23-48.

Salager-Meyer, F. (2001). From self-highlightedness to self-effacement: a genre-based study of the socio-pragmatic function of criticism in medical discourse. LSP and professional communication (2001-2008), 1(2).

Salager-Meyer, F. (2002 ). Market-place, self confidence and criticism in medical editorials. Revista Canaria de Estudios Ingleses, 44, 65-78.

Salager-Meyer, F., \& Zambrano, N. (2001). The bitter sweet rhetoric of controversiality in nineteenth-and twentiethcentury French and English medical literature. Journal of Historical Pragmatics, 2(1), 141-174.

Salager-Meyer, F., Alcaraz Ariza, M. A., \& Zambrano, N. (2003). The scimitar, the dagger and the glove: Intercultural differences in the rhetoric of criticism in Spanish, French and English medical discourse (1930-1995). English for Specific Purposes, 22(3), 223-247.

Salager-Meyer, F., \& Ariza, M. Á. A. (2003). Academic criticism in Spanish medical discourse: a cross-generic approach. International Journal of Applied Linguistics, 13(1), 96-114.

Salager-Meyer, F., Alcaraz Ariza, M. Á., \& Pabón Berbesí, M. (2007). Collegiality, critique and the construction of scientific argumentation in medical book reviews: a diachronic approach. Journal of Pragmatics, 39(10), $1758-1774$.

Sellani, R. J., \& Harrington, W. (2002). Addressing administrator/faculty conflict in an academic online environment. The Internet and Higher Education, 5(2), 131-145.

Stotesbury, H. (2003). Evaluation in research article abstracts in the narrative and hard sciences. Journal of English for Academic Purposes, 2(4), 327-341.

Thetela, P. (1997). Evaluated entities and parameters of value in academic research articles. English for Specific Purposes, 16(2), 101-118.

Vassileva, I. (1997). Hedging in English and Bulgarian academic writing. Trends in linguistics studies and monographs, 104, 203-222. 